\title{
Mechanical Properties of Castor Oil Polymer Mortars
}

\author{
João Marciano Laredo dos Reis*, Eduardo Pereira Motta
Theoretical and Applied Mechanics Laboratory - LMTA, Mechanical Engineering Post Graduate Program-PGMEC, Universidade Federal Fluminense - UFF, Rua Passo da Pátria, 156 Bl, E sala 216, Niterói, RJ, Brazil

Received: September 18, 2013; Revised: August 21, 2014

\begin{abstract}
In the last years, ecological concerns have resulted in the interest to substitute petroleum-based materials by renewable resources-based ones. Natural oils constitute an excellent alternative for the development of natural composites. The aim of this work is to evaluate the use of natural polymer, manufactured from castor oil, as substitute to synthetic, epoxy and polyester, in polymer mortars matrices, with particular regards to compressive, flexural and fracture properties. Mechanical properties of castor oil polymer mortars are similar to epoxy based ones and significantly higher than polyester polymer mortars with improved flexural properties and less brittle failure.
\end{abstract}

Keywords: natural resins, polymer mortars, mechanical properties

\section{Introduction}

Polymer mortar (PM) is a cementless composite, made of inorganic aggregates bonded together by a thermoset resin binder, which substitutes the cement. PM was first developed in the 1950's and then became widely known in the 1970's '. The composition of PM is determined by its applications, and its strength is influenced by ratio of aggregate to resin content $^{2,3}$. PM is used very efficiently in precast components. Indeed, polymer concrete has previously been mainly used for industrial flooring, retouching of damaged concrete structures and underground pipes. In comparison with conventional Portland cement concrete, polymer concrete offers many advantages, such as higher strength, better chemical resistance and improved fracture toughness ${ }^{4,5}$.

Since thermoset polymers are derived from petroleum, which is a non-renewable resource it will end someday. Today's energy matrix is mainly based on fossil fuels like petroleum oil, coal and natural gas, which covers more than $80 \%$ of total worldwide energy consumption ${ }^{6}$. Petroleum oil represents more than one third according to the International Energy Agency. Petroleum products derive from crude oil and are processed in oil refineries. The majority of petroleum is converted several classes of fuels ${ }^{7}$. Also, refineries produce other chemicals, some of which are used in chemical processes to produce plastics.

Alternatives to petroleum-based products are one of the main interests of researchers ${ }^{8-13}$. Natural oils occur in nature, can be extracted and are renewable. Natural oils such as soybean, corn, tung, linseed and castor, when synthetized produces natural polymers. Plant oils, which are predominantly made up of triglyceride molecules, are ideal replacement material to manufacture bio-based polymeric matrix as they are renewable, offer comparable performance and of low cost when compared with petroleum-based polymer matrices. These materials have also environmental advantages over petroleum-based materials making them an

*e-mail: jreis@mec.uff.br attractive alternative ${ }^{14-18}$. Castor oil is one of these natural polymers. The oil is obtained from extracting or expressing the seed of the plant Ricinus Communis. Castor oil is a viscous, pale yellow non-volatile and non-drying oil with a bland taste and is sometimes used as a purgative. It has a slight characteristic odour while the crude oil tastes slightly acrid with a nauseating after-taste ${ }^{19}$. India is the largest producer of castor oil followed by China and Brazil ${ }^{20}$. In Brazil, castor oil is locally known as mamona oil and is now being mainly used to produce biodiesel. Castor oil is unique in that it possesses both unsaturation and nonconjugated hydroxyl function. Castor oil was subjected to many familiar organic reactions to form useful derivatives, which can undergo radical or condensation polymerization reactions ${ }^{21}$. Castor oil can be synthetized as polyurethane resins, which are attractive due to their structural versatility (as elastomer, thermoplastic, thermosetting, rigid and flexible foams). They still present the particularity to be more compatible to vegetable fibers in relation to other resins, due to possible reaction of hydroxyl groups of the fibers and the isocyanate groups of the polyurethane $22-27$.

The proposal of this work is to study the mechanical properties, compressive, flexural and fracture, of polymer mortars manufactured with a polyurethane resin derived from castor oil and compare to synthetic polymers. The fabrication process development and the mechanical characterization of this new composite material are essential for its structural or functional application, presenting a great potential in the construction industry.

\section{Material and Methods}

\subsection{Materials}

Polymer mortar formulations were prepared by mixing foundry sand and castor oil polyurethane resin. Resin content was 10 and $12 \%$ in order to optimize mortar formulations. 
The aggregate was foundry sand with a homogeneous grain size, with uniform grains and a mean diameter of $300 \mu \mathrm{m}$, with finesses modulus between 3 and 5 . The specific gravity of the foundry sand was $2.63 \mathrm{~g} / \mathrm{cm}^{3}$. The foundry sand was previously oven dried and then, added to the castor oil resin to reduce moisture content, insuring a good bond between the natural polymer and the inorganic aggregate.

The employed thermosetting castor oil polyurethane resin was developed by the Group of Analytic Chemistry and Technology of Polymers, USP, São Carlos, Brazil and was manufactured and provided by Plural Brazil. Table 1 presents the castor oil polyurethane resin used in this research $^{22,23}$.

The castor oil polyurethane resin consists of two components, polyol and pre-polymer. The polyol was synthesized from the castor oil and the tri-functional polyester with hydroxyl index of $330 \mathrm{mg} \mathrm{KOH} / \mathrm{g}$ was obtained. The pre-polymer was synthesized from diphenylmethane diisocyanate (MDI) and pre- polymerized with a polyol also derived from castor oil, keeping a percentage of isocyanate free for posterior reaction. The approximate densities of the pre-polymer and polyol were 1.17 and $0.98 \mathrm{~g} / \mathrm{cm}^{3}$, respectively. The castor oil resin was processed mixing the procepolyol and pre-polymer in a weight ratio of $1: 1$.

Castor oil polyurethane polymer mortars fracture specimens were compacted in a steel mold. The specimens were cured at $110^{\circ} \mathrm{C}$ for 3 hours following manufacturer recommendation.

\subsection{Test method}

To determine the compressive properties, cylindrical polymer mortar specimens with $\phi 50 \times 100 \mathrm{~mm}$ were tested at a loading rate of $1.25 \mathrm{~mm} \mathrm{~min}^{-1}$, according to the ASTM C39- $05^{28}$ standard. Prismatic polymer mortar beams with $40 \mathrm{~mm} \times 40 \mathrm{~mm}$ x $160 \mathrm{~mm}$ were tested in by three-point bending up to failure at a loading rate of $1 \mathrm{~mm} \mathrm{~min}^{-1}$, with a span length of $100 \mathrm{~mm}$, according to the RILEM specification TC113/PCM- $8^{29}$. Despite the very short span compared to the thickness, shear effect was disregarded.

Table 1. Castor oil polyurethane resin properties.

\begin{tabular}{lc}
\hline \multicolumn{1}{c}{ Property } & $\begin{array}{c}\text { Castor oil } \\
\text { polyurethane }\end{array}$ \\
\hline Color & Dark yellow \\
Density $\left(\mathrm{g} / \mathrm{cm}^{3}\right)$ & 1.1 \\
Hardness shore D & 70 \\
Modulus of elasticity $(\mathrm{GPa})$ & 2.0 \\
Glass transition temperature $-\mathrm{Tg}\left({ }^{\circ} \mathrm{C}\right)$ & 60 \\
\hline
\end{tabular}

Polymer mortar is considered an isotropic material and the plane cross-section theory was assumed.

To determine the fracture properties, the Two Parameter Method (TPM) ${ }^{30}$ was used. This method is a direct method to calculate critical stress intensity factor, $\mathrm{K}_{\mathrm{Ic}}$, which is a measurement of a material's resistance to crack extension when the stress state near the crack tip is predominantly plane strain, limiting the plastic deformation, and the opening mode monotonic load is applied. Also the fracture energy was calculated according to RILEM ${ }^{31}$. Fracture tests were conducted using a universal testing machine with a cross- head speed of $0.5 \mathrm{~mm} \mathrm{~min}^{-1}$. The crack mouth opening displacement (CMOD) was measured using a COD gauge clipped at the bottom of the beam and held in position by two $1.5 \mathrm{~mm}$ steel knife edges glued to the specimen.

\section{Results and Discussion}

Polymer mortars manufactured with castor oil test results are presented in Table 2 and are compared to previous work done by the author where synthetic polymer resins were used as polymer matrix ${ }^{32,33}$.

According to Table 2 it can be seen that, as happen to synthetic polymer mortars, epoxy and polyester ${ }^{26}$, increasing the quantity of resin content mechanical properties increase. Increasing from $10 \%$ to $12 \%$ of resin content compressive strength increases $16.6 \%$, an elevation of $15.9 \%$ in the flexural strength is observed, $6 \%$ in the fracture toughness increment and $98.5 \%$ increase in the fracture energy is reported.

Comparing $12 \%$ castor oil polymer mortars to $12 \%$ epoxy polymer mortars, the compressive strength is similar, castor oil polymer mortars has $2.2 \%$ lower compressive strength and $1.5 \%$ less fracture toughness. Despite compressive strength and fracture toughness slight decrease, flexural strength significantly increases, 39.1\%, and fracture energy, where the work, which is the area under load vs. displacement curve, takes much importance, increases $243.2 \%$, indicating lower crack propagation. Analyzing castor oil polymer mortars test results and comparing to $12 \%$ polyester polymer mortars properties the increase is significantly high. Comparing the results of $10 \%$ castor oil resin content, an increase in the compressive, flexural strength, fracture toughness and energy is reported. Castor oil polymer mortar compressive strength is $33.1 \%$ higher, flexural strength is $143.9 \%$ higher, $57.3 \%$ elevation in the fracture toughness and $314.7 \%$ higher fracture energy is observed. Calculating the results of $12 \%$ castor oil resin content and comparing to $12 \%$ of polyester resin content the increase in the mechanical properties are even higher.

Table 2. Castor oil polymer mortar test results.

\begin{tabular}{|c|c|c|c|c|}
\hline Polymer Mortars & $\begin{array}{c}\text { Compressive Strength } \\
\text { (MPa) }\end{array}$ & $\begin{array}{c}\text { Flexural Strength } \\
\text { (MPa) }\end{array}$ & $\mathrm{K}_{\mathrm{Ic}}(\mathrm{MPa})$ & $\mathrm{G}_{\mathrm{f}}(\mathrm{Nm})$ \\
\hline $10 \%$ Castor Oil & $32.46 \pm 0.81$ & $19.08 \pm 0.64$ & $1.84 \pm 0.16$ & $635.97 \pm 22.97$ \\
\hline $12 \%$ Castor oil & $37.86 \pm 0.75$ & $22.11 \pm 2.26$ & $1.95 \pm 0.20$ & $1262.61 \pm 89.02$ \\
\hline $12 \%$ Epoxy $^{32,33}$ & $38.73 \pm 1.82$ & $15.87 \pm 0.57$ & $1.98 \pm 0.04$ & $367.91 \pm 30.23$ \\
\hline $12 \%$ Polyester $^{32,33}$ & $24.39 \pm 3.25$ & $7.82 \pm 0.96$ & $1.17 \pm 0.22$ & $153.37 \pm 11.94$ \\
\hline
\end{tabular}




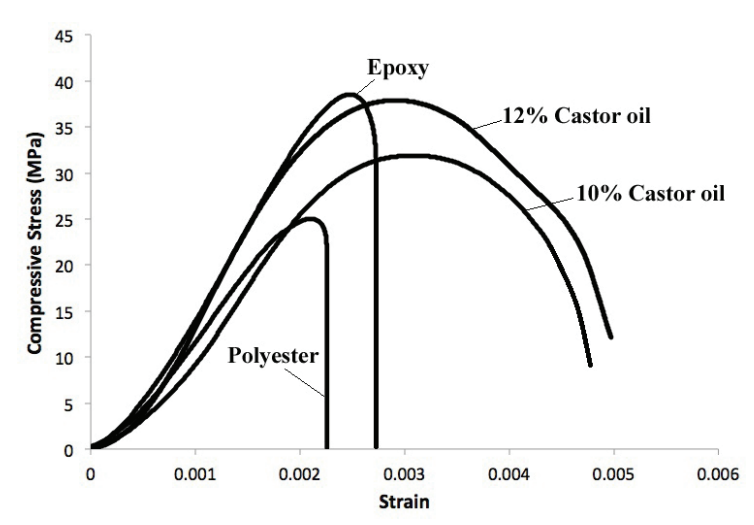

Figure 1. Typical compressive stress vs. strain of castor oil and synthetic polymer mortars.

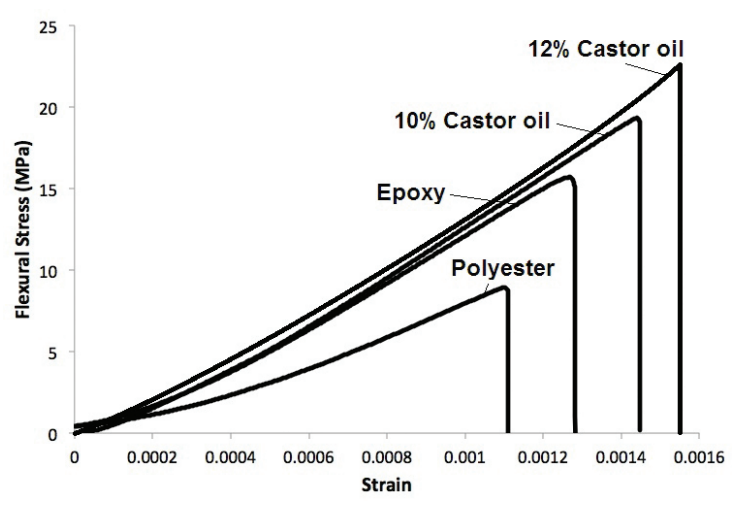

Figure 2. Typical flexural stress vs. strain of castor oil and synthetic polymer mortars.

Figure 1 presents the typical compressive stress vs. strain of castor oil polymer mortars and the synthetic polymer mortars.

According to Figure 1 it can be seen that castor oil produces less brittle failure compared to epoxy and polyester polymer mortars. Polymer mortars containing $12 \%$ of castor oil polyurethane resin displays similar high compressive strength to epoxy polymer mortars but strain at failure is almost 2 times higher. Also, compressive stiffness of $12 \%$ castor oil polymer mortar is similar to epoxy ones. Figure 2 displays the typical flexural stress vs. strain of castor oil polymer mortars and the synthetic polymer mortars.

Analyzing Figure 2 it can be seen that castor oil polymer mortars have similar flexural stiffness to epoxy polymer mortars but higher flexural strength following the concept that higher resin content higher strength. Polyester polymer mortars present the worst flexural result, low flexural stiffness and strength in comparison to castor oil polymer mortars. Typical load vs. CMOD curves of castor oil and synthetic polymer mortars are presented in Figure 3.

From Figure 3, when fracture mechanics parameters are analyzed, it can be seen that $12 \%$ castor oil polymer mortars display lower stiffness compared to $10 \%$ castor oil, epoxy and polyester polymer mortars, but a significant decrease in brittleness is observed. This can be visualized by the slope angle in the linear section. As castor oil content increases

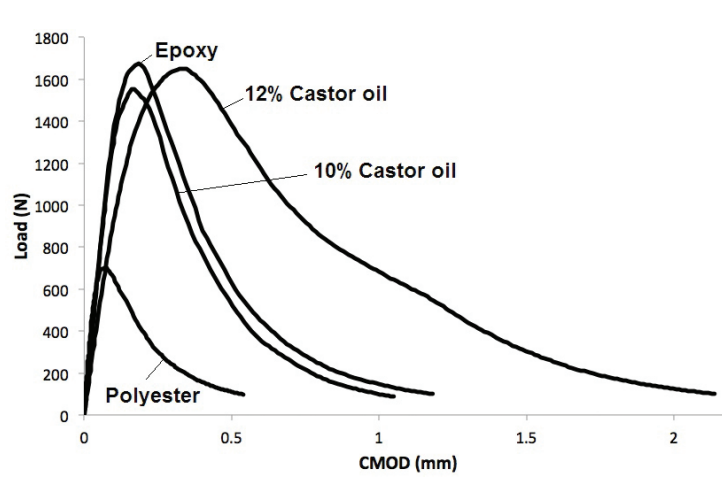

Figure 3. Typical Load vs. CMOD of castor oil and synthetic polymer mortars.

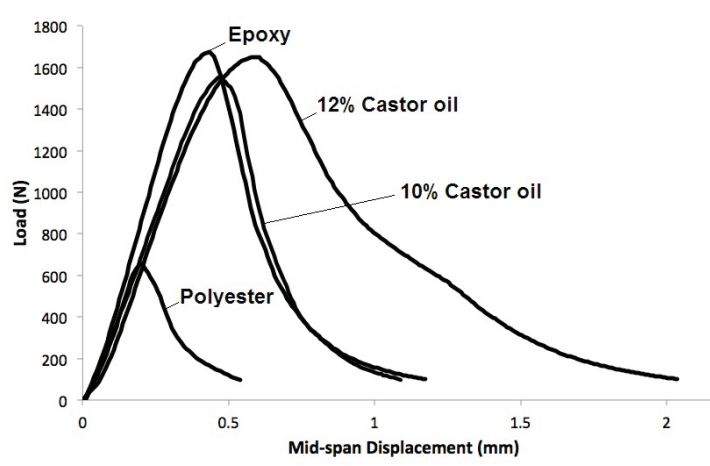

Figure 4. Typical load vs. mid-span displacement curves of castor oil and synthetic polymer mortars.

in polymer mortars mixture, less brittle polymer mortars become. Again, polyester polymer mortars displays low resistance to crack propagation, despite the stiffness. The typical load vs. mid-span displacement curves of castor oil and synthetic polymer mortars are presented in Figure 4.

Analyzing Figure 4, increasing castor oil resin content in polymer mortars mixture higher energy can be absorbed since the area under the load vs. mid-span displacement is higher than epoxy and polyester polymer mortars, thus, elevating the resistance to create a fracture surface area. Also, less brittle behavior can be reported as castor oil content increases in the polymer matrix. This can be explained by the higher elongation at break ${ }^{23}$ from polyurethane resins compared to epoxy and polyester.

\section{Conclusions}

In this research work, the effect of using natural polymer resin produced from castor oil seeds as substitute of synthetic polymer resins, epoxy and polyester in polymer mortars matrix was analyzed. The compressive, flexural and fracture behavior were calculated and quantified.

Substituting synthetic polymer resins by natural resin produces a composite material that brings economical and energy saving benefits from an ecological point of view.

As content of castor oil increases better mechanical properties are observed. $12 \%$ castor oil polymer mortars 
produce similar results to epoxy polymer mortars in numbers. However, significant less brittle failure and a considerably increase in the flexural strength and fracture energy is observed, especially when compared to polyester polymer mortars. Mechanical properties of castor oil polymer mortars are higher than polyester polymer mortars even for $10 \%$ castor oil resin composites.

A significant improve in the fracture energy of castor oil polymer mortars is reported when compared to synthetic polymer mortars, increasing the resistance to create a fracture surface area producing a composite material with

\section{References}

1. American Concrete Institute Committee. Polymer Concretestructural applications. State-of-the-Art Report. Detroit, Michigan: ACI; 1997. ACI Manual of Concrete Practice, Part 5.

2. Ribeiro MCS, Tavares CML, Figueiredo M, Ferreira AJM and Fernandes AA. Bending characteristics of resin concretes. Materials Research. 2003; 6(2):247-254. http://dx.doi. org/10.1590/S1516-14392003000200021.

3. Reis JML. Effect of textile waste on the mechanical properties of polymer concrete. Materials Research. 2009; 12(1):63-67. http://dx.doi.org/10.1590/S1516-14392009000100007.

4. Agavriloaie L, Oprea S, Barbuta M and Luca F. Characterization of polymer concrete with epoxy polyurethane acryl matrix. Construction \& Building Materials. 2012; 37:190-196. http:// dx.doi.org/10.1016/j.conbuildmat.2012.07.037.

5. Gorninski JP, Dal Molin DC and Kazmierczak CS. Comparative assessment of isophtalic and orthophtalic polyester polymer concrete: Different costs, similar mechanical properties and durability. Construction \& Building Materials. 2007; 21(3):546555. http://dx.doi.org/10.1016/j.conbuildmat.2005.09.003.

6. International Energy Agency. Key World Energy Statistics; 2012.

7. Irion WW and Neuwirth OS. Oil Refining. In: Ullmann's Encyclopedia of Industrial Chemistry. Weinheim: WileyVCH; 2005. http://dx.doi.org/10.1002/14356007.a18_051

8. Zhang X, Gao D, Wu X and Xia K. Bulk plastic materials obtained from processing raw powders of renewable natural polymers via back pressure equal channel angular consolidation (BP-ECAC). European Polymer Journal. 2008; 44(3):780-792. http://dx.doi.org/10.1016/j.eurpolymj.2007.12.011.

9. Mosiewicki MA and Aranguren MI. A short review on novel biocomposites based on plant oil precursors. European Polymer Journal. 2013; 49(6):1243-1256. http://dx.doi.org/10.1016/j. eurpolymj.2013.02.034.

10. Sharma V and Kundu PP. Addition polymers from natural oils-A review. Progress in Polymer Science. 2006; 31(11):9831008. http://dx.doi.org/10.1016/j.progpolymsci.2006.09.003.

11. Ratajska M and Boryniec S. Physical and chemical aspects of biodegradation of natural polymers. Reactive \& Functional Polymers. 1998; 38(1):35-49. http://dx.doi.org/10.1016/S13815148(98)00031-5.

12. Zhang X, Gozukara Y, Sangwan P, Gao D and Bateman S. Biodegradation of chemically modified wheat glutenbased natural polymer materials. Polymer Degradation \& Stability. 2010; 95(12):2309-2317. http://dx.doi.org/10.1016/j. polymdegradstab.2010.09.001.

13. Sionkowska A. Current research on the blends of natural and synthetic polymers as new biomaterials [Review]. Progress high energy absorbing, which is very important for structures under dynamic and impact conditions.

\section{Acknowledgements}

The authors thank the Research Foundation of the State of Rio de Janeiro (FAPERJ) and The Brazilian National Council for Scientific and Technological Development (CNPq) for supporting part of the work presented here. Also, authors would like to thank Plural Indústria e Comércio de Produtos Químicos Ltda for providing the castor oil polyurethane resin.

in Polymer Science. 2011; 36(9):1254-1276. http://dx.doi. org/10.1016/j.progpolymsci.2011.05.003.

14. Malmstein M, Chambers AR and Blake JIR. Hygrothermal ageing of plant oil based marine composites. Composite Structures. 2013; 101:138-143. http://dx.doi.org/10.1016/j. compstruct.2013.02.003.

15. Haq M, Burgueño R, Mohanty AK and Misra M. Hybrid bio-based composites from blends of unsaturated polyester and soybean oil reinforced with nanoclay and natural fibers. Composites Science and Technology. 2008; 68(15-16):33443351. http://dx.doi.org/10.1016/j.compscitech.2008.09.007.

16. Liu ZS, Erhan SZ and Calvert PD. Solid freeform fabrication of epoxidized soybean oil/epoxy composite with bis or polyalkyleneamine curing agents. Composites. Part A, Applied Science and Manufacturing. 2007; 38(1):87-93. http://dx.doi. org/10.1016/j.compositesa.2006.01.009.

17. Pfister DP and Larock RC. Green composites from a conjugated linseed oil-based resin and wheat straw. Composites. Part A, Applied Science and Manufacturing. 2010; 41(9):1279-1288. http://dx.doi.org/10.1016/j.compositesa.2010.05.012.

18. Jacob M, Thomas S and Varughese KT. Mechanical properties of sisal/oil palm hybrid fiber reinforced natural rubber composites. Composites Science and Technology. 2004; 64(7-8):955-965. http://dx.doi.org/10.1016/S0266-3538(03)00261-6.

19. Ogunniyi DS. Castor oil: a vital industrial raw material. Bioresource Technology. 2006; 97(9):1086-1091. http://dx.doi. org/10.1016/j.biortech.2005.03.028. PMid:15919203

20. Food And Agricultural Organization of United Nations. Economic And Social Department: The Statistical Division. Rome; 2008.

21. Mistri E, Routh S, Ray D, Sahoo S and Misra M. Green composites from maleated castor oil and jute fibres. Industrial Crops and Products. 2011; 34(1):900-906. http://dx.doi. org/10.1016/j.indcrop.2011.02.008.

22. Claro Neto S. Physical chemistry characterization of a polyurethane derived from castor oil used for bone implants. [Tese]. São Carlos: University of São Paulo; 1997.

23. Silva RV. Composite based on polyurethane resin derived from castor oil and vegetable fibers. [Tese]. São Carlos: University of São Paulo; 2003.

24. Silva RV, Spinelli D, Bose Filho WW, Claro Neto S, Chierice GO and Tarpani JR. Fracture toughness of natural fibers/ castor oil polyurethane composites. Composites Science and Technology. 2006; 66(10):1328-1335. http://dx.doi. org/10.1016/j.compscitech.2005.10.012.

25. Miléo PC, Mulinari DR, Baptista CARP, Rocha GJM and Gonçalves AR. Mechanical Behaviour of Polyurethane from Castor oil Reinforced Sugarcane Straw Cellulose Composites. Procedia Engineering. 2011; 10:2068-2073. http://dx.doi. org/10.1016/j.proeng.2011.04.342. 
26. Fiorelli J, Sartori DL, Cravo JCM, Savastano Junior H, Rossignolo JA, Nascimento MF, et al. Sugarcane Bagasse and Castor Oil Polyurethane Adhesive-based Particulate Composite. Materials Research. 2013; 16(2):439-446. http:// dx.doi.org/10.1590/S1516-14392013005000004.

27. Dias FM and Lahr FAR. Alternative castor oilbased polyurethane adhesive used in the production of plywood. Materials Research. 2004; 7(3):413-420. http://dx.doi. org/10.1590/S1516-14392004000300007.

28. American Society for Testing and Materials. ASTM C39/ C39M - 05e1 Standard Test Method for Compressive Strength of Cylindrical Concrete Specimens. ASTM; 2005.

29. CPT PC-8. Method of test for flexural strength and deflection of polymer-modified mortar. TC 113. London: RILEM; 1995.
30. RILEM TC89-FMT. Fracture mechanics of concrete test methods. Materials and Structures. 1991; 23:457-460.

31. RILEM. 50-FMC. Determination of fracture energy of mortar and concrete by means of three-point bend test on notched beams. Materials and Structures. 1985; 18:285-290.

32. Reis JML, Chianelli-Junior R, Cardoso JL and Marinho FJV. Effect of recycled PET in the fracture mechanics of polymer mortar. Construction \& Building Materials. 2011; 25(6):27992804. http://dx.doi.org/10.1016/j.conbuildmat.2010.12.056.

33. Reis JML and Carneiro EP. Evaluation of PET waste aggregates in polymer mortars. Construction \& Building Materials. 2012; 27(1):107-111. http://dx.doi.org/10.1016/j. conbuildmat.2011.08.020. 